\title{
The Development and Use of Tools to Support Workplace Hand-Arm Vibration Exposure Evaluation
}

\author{
Paul Pitts ${ }^{1}$. Paul Brereton ${ }^{2}$
}

Received: 2 December 2015 / Accepted: 5 January 2016 / Published online: 9 February 2016

(C) The Author(s) 2016. This article is published with open access at Springerlink.com

\begin{abstract}
Long-term exposure to hand-arm vibration (HAV) from powered machinery is known to be responsible for damage to the hand and arm. To protect workers, employers are required to apply appropriate measures to control vibration exposures. A key part of the process of effective assessment and control of vibration risks is the evaluation of vibration exposures. The vibration data required for exposure evaluation need to be suitable and sufficient to enable the appropriate actions to be taken. In Great Britain, the Health and Safety Executive (HSE) has provided tools designed to simplify exposure evaluation as part of employers' risk assessments for vibration. These tools help to demystify the process and help employers move as quickly as possible from the evaluation of exposures to actively controlling risk. This paper discusses the tools provided by HSE designed to support the HAV risk assessment process. It reviews existing tools including the "rule of thumb", which provides an initial indicator to likely risks, and the points system and calculator tool, which simplify the exposure calculation processes. The paper also introduces a table of indicative vibration magnitudes, which has been developed for a revision of HSE guidance to help employers to achieve initial estimates of likely vibration exposures. The objective of all these tools is to enable employers to get efficiently from risk assessment to making decisions about the requirements for vibration control and getting those controls implemented.
\end{abstract}

Keywords Vibration $\cdot$ Hand-arm $\cdot$ Risk assessment $\cdot$ Employer duties $\cdot$ Indicators

\section{Introduction}

Long-term exposure to hand-arm vibration (HAV) from powered machinery is known to be responsible for damage to the hand and arm. Collectively referred to as HAV syndrome, workers may suffer a from a range of conditions representing damage to the vascular system [such as vibration white finger (Fig. 1) where circulation to the fingers is disrupted], sensorineural system (numbness and tingling in the hand and fingers) and the musculoskeletal and soft tissue system (such

Paul Pitts

paul.pitts@hsl.gsi.gov.uk

Harpur Hill, Buxton SK17 9JN, UK

2 Redgrave Court, Merton Rd, Bootle, Merseyside L20 7HS, UK as joint pain and lack of grip strength or conditions such as carpal tunnel syndrome).

In Great Britain, the comparison of values for likely workplace exposures with exposure action and limit values defined in legislation [1] (and originally specified by EU Directive [2]) is an important part of the process of determining the actions for exposure control and health surveillance required of a duty holder. HAV exposure assessments must account for both the magnitudes of the vibration and the durations of exposures during a working day. In many cases, employers have put more effort into quantification of vibration magnitudes and daily exposure than was required for identifying and implementing practical vibration controls.

The purpose of the risk assessment is to identify whether control is required and what control measures are appropriate. A key part of the assessment is some form of exposure evaluation. The precision required of that evaluation will 


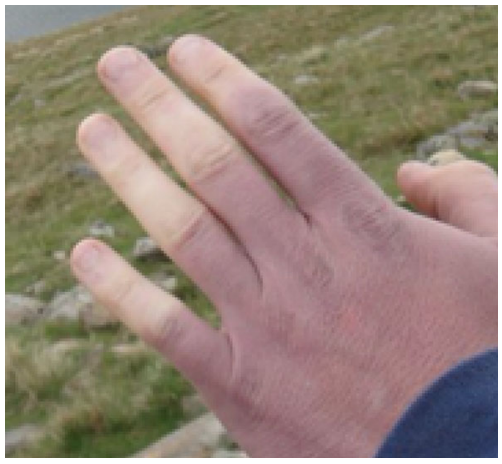

Fig. 1 Vibration white finger

depend on where an employer is in the process of determining and controlling risks. The vibration data required for risk assessment need to be suitable and sufficient to enable the correct action to be taken.

The Health and Safety Executive (HSE) provides guidance for HAV through its web pages (www.hse.gov.uk/ vibration/hav) and guidance books. This paper discusses tools provided by HSE designed to support the HAV risk assessment and exposure evaluation process and introduces a table of indicative vibration magnitude values that has been developed for a planned revision of HSE guidance L140 [1] to either help employers with their initial estimates of vibration exposures or to provide a sources of validation of data from other sources. The objective of all these tools is to enable employers to get efficiently from exposure evaluation to making appropriate decisions about the requirements for vibration control and getting those controls implemented.

\section{Evaluation of HAV Exposure}

The basis for the evaluation of vibration risk is provided in ISO 5349-1:2001 [3] where daily vibration exposure $A(8)$ is defined as:

$A(8)=\sqrt{\left(\frac{1}{T_{0}} \sum a_{\mathrm{hvi}}^{2} T_{i}\right)}$,

where $T_{0}$ is the reference duration of $8 \mathrm{~h}(28,800 \mathrm{~s}), a_{\mathrm{hvi}}$ is the frequency-weighted ( $W_{\mathrm{h}}$ weighting) acceleration total value of the machine or process $i$, and $T_{i}$ is the duration of exposure to the machine or process $i$.

This equation is the basis of all the evaluation tools provided to employers, but for these tools to be effective, the details of the mathematical relationships should not visible to the user.
Table 1 Rule of thumb

\begin{tabular}{lll}
\hline & $\begin{array}{l}\text { Time to exposure } \\
\text { action value } \\
\left(A(8)=2.5 \mathrm{~m} / \mathrm{s}^{2}\right)\end{array}$ & $\begin{array}{l}\text { Time to exposure } \\
\text { limit value } \\
\left(A(8)=5 \mathrm{~m} / \mathrm{s}^{2}\right)\end{array}$ \\
\hline Rotary tools & $1 \mathrm{~h}$ & $4 \mathrm{~h}$ \\
Percussive tools & $1 / 4 \mathrm{~h}$ & $1 \mathrm{~h}$ \\
\hline
\end{tabular}

\section{Vibration Exposure Tools}

\subsection{Rule-of-Thumb}

When employers are first faced with having to control vibration in the workplace, they often do not appreciate the need to consider both vibration magnitudes and exposure times. To those with knowledge and understanding of workplace vibration, it is clear that machines used for short periods are unlikely to present a vibration risk. But, how short is short? Some machines produce much higher vibration magnitudes than others, so which machines present the greatest risk?

As a general rule, most percussive (hammer-action) machines produce higher magnitudes of frequency-weighted vibration than most machines with purely rotary action. There are exceptions to this statement, particularly where manufacturers have invested in the development of lowvibration machines; however it is a useful basis for initial risk assessment. Rotary machines tend to have vibration magnitudes in the 5 to $10 \mathrm{~m} / \mathrm{s}^{2}$ region, percussive tools are more likely to be between 10 and $20 \mathrm{~m} / \mathrm{s}^{2}$. Based on these broad assumptions, HSE produced a rule-of-thumb guide for vibration exposures (shown in Table 1). The rule of thumb gives an indication of the machine operation time it might take for modern, well-designed and well-maintained tools to reach the exposure action and exposure limit values.

The rule of thumb is a very approximate guide to the relationship between machine usage and exposure times that might be associated with vibration risks. Alongside, this guidance HSE includes warnings about the limitations of its use, for example: the use of older designs of tool and poor maintenance can result in the criterion values being reached much more quickly. While such caveats are necessary, the rule of thumb does provide a simple and effective starting point for many employers.

\subsection{Vibration Exposure Points System}

In most cases, a person's daily exposure is a result of more than one type of exposure: a fettler may use a grinder and a disc cutter, a worker in horticulture may do both lawn cutting and strimming. Many employers find Eq. 1 difficult to apply; daily exposure values cannot be simply added and mistakes 


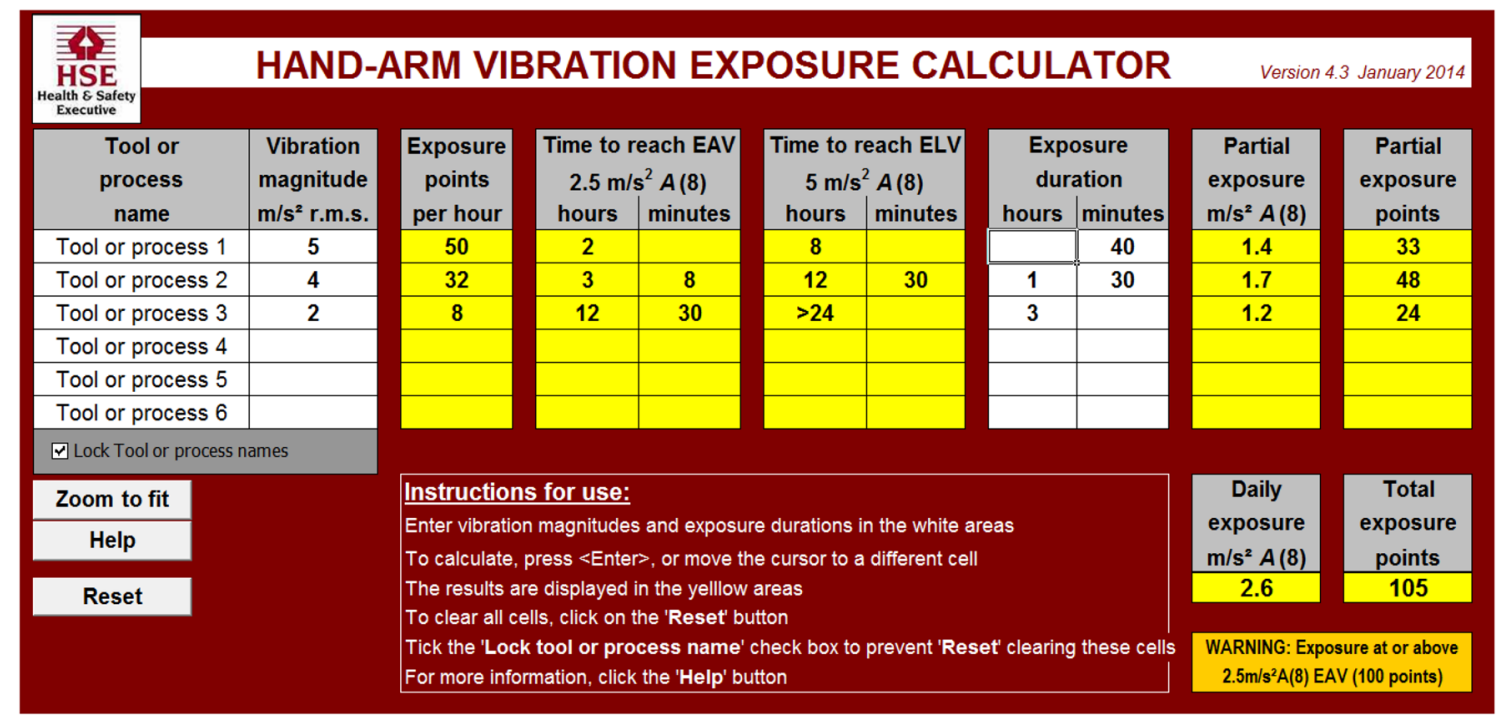

Fig. 2 HSE hand-arm vibration exposure calculator

are easily made. One way of simplifying the process is to use an alternative representation of exposures. For guidance book L140 [1], HSE introduced the exposure points system, such that an acceleration exposure in points $(n)$ is given by:

$n=100\left(\frac{a_{\mathrm{hv}}}{2.5}\right)^{2} \frac{T}{T_{0}}$,

where $a_{\mathrm{hv}}$ is the frequency-weighted acceleration total value, and $T$ is the time exposed to acceleration $a_{\mathrm{hv}}$. When points are used, the exposure action value is the equivalent of 100 points and the exposure limit value is 400 points. The principle advantage of points is that exposures can simply be added, so if in one day a worker receives 50 points from the use of one tool, and 25 points from another, then the total points accumulated over the day is $50+25=75$ points.

Exposure points may also be used to track exposures from individual tools, as the number of points per hour from any tool, $n_{1 \mathrm{~h}}$, is given by:

$n_{1 \mathrm{~h}}=2 a_{\mathrm{hv}}^{2}$.

For example, a machine producing a vibration magnitude of $5 \mathrm{~m} / \mathrm{s}^{2}$ provides 50 points per hour, so could be used for $2 \mathrm{~h}$ before the 100 point action value is exceeded.

\subsection{HSE HAV Calculator}

The HSE HAV calculator is an Excel spreadsheet which can be downloaded from the HAV pages of the HSE web site, at www.hse.gov.uk/vibration/hav/hav.xls. The calculator is designed to calculate daily vibration exposure estimates; enabling the user to make adjustments, to see how changes to work patterns and machines might affect exposures. The calculator is also a valuable aid to prioritising actions, since it can clearly identify the machines or process that contribute most to a worker's daily vibration exposure.

Figure 2 shows the calculator with some example data. The example data illustrates a worker using three tools (or undertaking three different processes). It shows the estimated vibration magnitudes for each tool or process and estimated exposure times. The calculator then shows the total daily exposure estimate (in this case $2.6 \mathrm{~m} / \mathrm{s}^{2} A(8)$ or 105 points) and shows which tools or processes contribute most to that exposure (in this case tool 2 followed by tool 1 ). In this example, effort put into reducing the exposures to tools 2 and 1 is likely to have greater benefit than any effort put into reducing the exposure from the tool or process that is used for longest time (tool 3).

\section{Sources of Vibration Magnitude Data}

\subsection{Manufacturer Declared Values}

Vibrating machinery supplied into Europe must have, in the operating instructions, information on vibration emissions [4]. To comply with this requirement, manufacturers carry out HAV measurements according to standardised test codes. These harmonised standards provide recognised methods of complying with the requirement for emission declaration.

The declaration values have two objectives. First they should allow potential users to select a machine with the lowest vibration; so the standard test must be able to rank tools according to their vibration emissions. Second, the declared value ought to provide information that is indicative of real use, representing the upper quartile of vibration mag- 
nitudes resulting from intended uses of the machinery [5]. For ranking of machine vibration emissions, the standards are generally quite effective. However, standard tests are not so good at representing real in-use vibration, and for many machines the manufacturer's declared, the emission is likely to underestimate risk [6].

\subsection{Measured Vibration Magnitudes}

Measurement of vibration ought to be a last resort for most users of vibrating machinery. Sufficient data should be available from sources other than direct measurement to enable an assessment of risk that is suitable for deciding the control actions that need to be taken. However, in some cases, measurement is unavoidable. It may be that adequate data are not available on the machines being used, or the exposure estimates are otherwise too close to the action thresholds to be confident of the control actions necessary.

Where measurement is carried out it should be in accordance with the relevant international standards. ISO 53491:2001 [3] provides the basic definitions and measurement specifications, ISO 5349-2:2001 [7] provides guidance on practical workplace measurement, and ISO 8041:2005 [8] provides specification for the measurement instrumentation.

\subsection{Indicative Data}

Tables of indicative vibration values for machine categories are available from some sources. These tables can be very useful at various stages of the assessment process. They provide numbers that can be used in initial risk assessments and may be sufficient to make decisions on control requirements. They can help to confirm that measurement results or manufacturer's data are reasonable; showing the range of vibration values expected for machine types.

HSE has been developing indicative data for the planned update to the guidance to the HAV regulations L140 [1]. Such data must be based on reliable, representative datasets, covering a wide range of industries and machine types. Ideally it should guide employers towards using data that will tend to over-protect rather than under-protect workers.

\subsubsection{Source Data for Indicative Tables}

The HSE's Buxton Laboratory operates a HAV database, which has been used to collect data from HAV measurements made since the 1990s. The database forms an integral part of HSE's workplace HAV analyses and is systematically populated with data on new workplace HAV measurements.

The database is designed to capture essential vibration measurement information along with details of the machines being used, including power source, mass and accessories as well as information on parameters such as the work activity, materials used, location, worker occupation and industry group.

The vibration measurement information in the database contributed to the European Commission's non-binding guidance on implementing the Physical Agents (Vibration) Directive 2002/EC/44 [9]. It has also been applied to the evaluation of alternative frequency weightings for evaluation of HAV (for example: Pitts et al. [10]).

\subsubsection{Summarising Machine Data}

The primary aim of the HAV database is to provide a repository of representative vibration magnitudes for different machine types that can be referred to by the HSE and used for exposure assessment if required. The database collects vibration measurement records against individual machines, for one set of operating conditions, at one location. When using the database to analyse across tool types, it is important to understand the biases that may inadvertently be introduced by simple statistical analysis of the whole dataset.

Most workplace measurements involve making multiple measurements of an individual machine. If a single representative value for a category of machines is required, the multiple datasets need to be averaged to produce a single value for each machine (to avoid biasing the data towards machines for which many measurements have been made). When combining data, the prime consideration has to be producing a dataset that is representative of a machine type, incorporating the variations introduced by evaluations with different (experienced) operators and different work activities. This averaging is not always straightforward; for example, in HSE's database data for one unique machine may have been measured at more than one measurement site.

To further complicate the process of isolating unique machines, some machines could be categorised in different sub-types, based on the inserted tool being used (for example, a drill can be termed a hammer drill if fitted with a standard drill bit or a core-drill when fitted with a diamond core bit). The unique machine identification included information to separate out these different applications.

\subsubsection{Identifying Machine Sub-groups}

For any one machine group, there is a distribution in measured vibration values. Much of the variation between results is due to differences between machines, operators, materials and inserted tools or consumables. However, in some cases there are sub-groups within machine types that are characterised by quite different vibration magnitudes. In some cases, these sub-groups are predictable, and differences between these sub-groups were clear within the datasets. In other cases, the parameters causing the distinct groups within 
Fig. 3 Illustration of vibration magnitude distributions for sub-categories of needle scalers

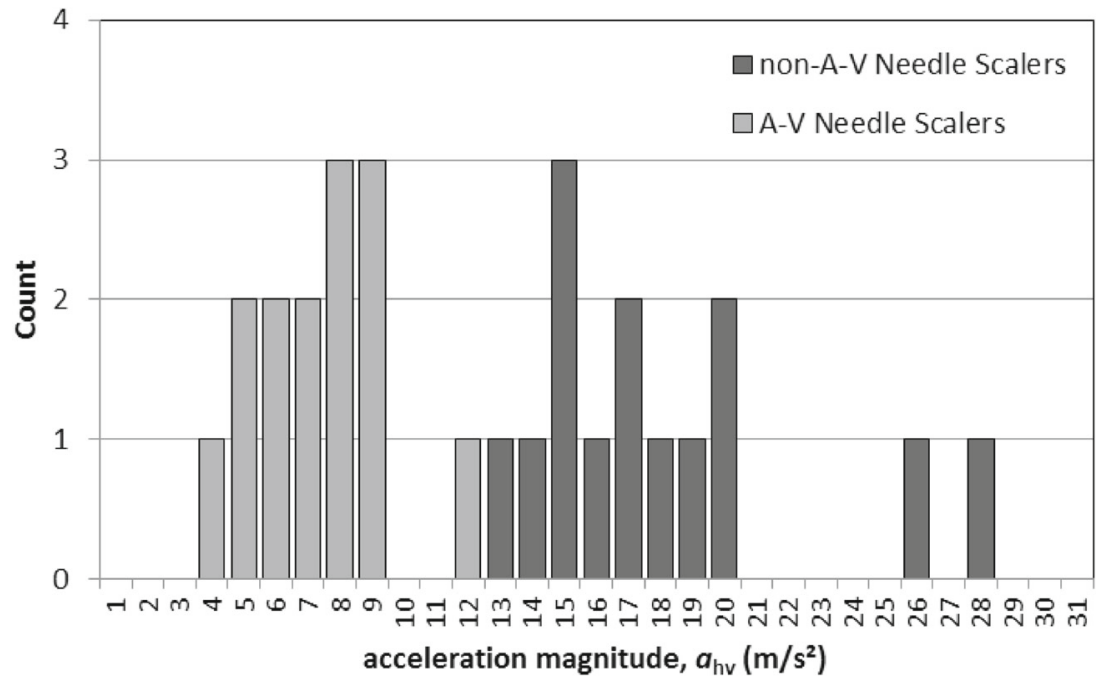

vibration distribution were less clear and prospective subgroupings had to be tested.

As an illustration, Fig. 3 shows the distribution of data from a collection of measurements on needle scalers. This distribution shows two clear distribution peaks. Where such distributions were evident, the data were broken into subgroups according to material, inserted tool size or type or fitted consumable to try and identify the likely reason for the different peaks. In the case of the needle scalers illustrated in Fig. 3, the difference between the sub-groups in the distribution is due to some tools having anti-vibration (A-V) features and others being standard (non-A-V) tools. The shading in Fig. 3 identifies the data from these two subgroups.

\subsection{Presentation of Data in Planned HSE Guidance}

When presenting vibration values in HSE guidance, it is important to make sure that the information is presented in a way that is appropriate for the target audience. In general, the audience for HSE guidance will have familiarity with general health and safety issues but may not be technically familiar with the topic of HAV. The audience is likely to be looking for a way to comply with all health and safety duties without needing an in-depth knowledge of the technical detail of any individual topic; HAV is just one of many issues they have to address.

The Control of Vibration at Work Regulations 2005 are aimed at reducing risks from HAV exposure. The exposure action and limit values are necessary to determine the actions required of employers; however, these are values that employers often focus on too much. By presenting numerical data in the guidance, there are dangers of the data contributing to a greater focus on just the numbers. Therefore, some consideration must be given as to how any numerical data are presented; ensuring that the data help the target audience not only just to assess the risks, but also to control those risks.

Figure 4 shows the 10th, 25th, 50th, 75th and 90th percentile values for all of the machine groups extracted from the HSE database. Data similar to this have previously been presented by the European Commission in non-binding guidance to implementing directive 2002/EC/44 [9] (the HAV data presented in this EC guide are also largely based on data from the HSE database). The presentational format in the EC guide is useful because it indicates not only the magnitudes of the vibration, but also the range of vibration values that might be expected with machine types. However, for a non-technical audience, looking for information to complete a simple risk assessment, this presentation provides too much information; there is a danger that the audience will not understand which numbers apply to them. It is therefore important to consider carefully which data are most suited to a non-technical audience.

Collated information on machine vibration is often valuable in the initial stages of carrying out risk assessments. For this reason, it is HSE's preference that such collated data are representative of the worst case vibration values, so that the result of the assessment is that workers are more likely to be over-protected than under-protected. This is the main reason why the 75th percentile is the preferred value for presentation as an initial value for risk assessment. However, it is also important to give some indication that the value given is only a representation of a range of possible values. The range of values will suggest to readers that, within a machine type, there may be opportunities to achieve lower vibration magnitudes, but some additional work is necessary to investigate machine options and refine the initial assessment. 


\begin{tabular}{|c|c|c|c|c|c|c|c|}
\hline \multirow{4}{*}{\begin{tabular}{|l} 
Key: \\
10\%ile-25\%ile \\
(25\%ile-Median
\end{tabular}} & & \multicolumn{6}{|c|}{ Acceleration magnitude, $a_{\mathrm{hv}}\left(\mathrm{m} / \mathrm{s}^{2}\right)$} \\
\hline & \multirow[b]{2}{*}{ Drills - Standard drill bit } & 0 & 10 & 15 & 20 & 25 & 30 \\
\hline & & 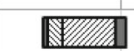 & & & & & \\
\hline & Drills - Hole saw & & & & & & \\
\hline \multirow{4}{*}{$\begin{array}{l}\text { घhedian-75\%ile } \\
\square 75 \% \text { ile-90\%ile }\end{array}$} & Drills - Core - 78 - $107 \mathrm{~mm}$ & & & & & & \\
\hline & Drills - Impact - 5 and $8 \mathrm{~mm}$ masonry bit & & & & & & \\
\hline & Drills - Impact - $13 \mathrm{~mm}$ masonry bit & & & & & & \\
\hline & Grinders - Angle $100-180 \mathrm{~mm}$ & & & & & & \\
\hline \multicolumn{8}{|c|}{ Grinders - Angle 125 and 100 mm - Flapper discs } \\
\hline \multicolumn{8}{|c|}{ Grinders - Angle 220 - $300 \mathrm{~mm}$} \\
\hline \multicolumn{8}{|c|}{ Grinders - Die } \\
\hline \multicolumn{8}{|c|}{ Grinders - Straight } \\
\hline \multicolumn{8}{|c|}{ Nail guns } \\
\hline \multicolumn{8}{|c|}{ Needle scalers - Non-vibration reduced } \\
\hline \multicolumn{8}{|c|}{ Needle scalers - Vibration reduced } \\
\hline \multicolumn{8}{|c|}{ Nibblers } \\
\hline \multicolumn{8}{|c|}{ Rammers } \\
\hline \multicolumn{8}{|c|}{ Reciprocating saws } \\
\hline \multicolumn{8}{|c|}{ Sanders - Random-orbital } \\
\hline \multicolumn{8}{|c|}{ Sanders - Orbital } \\
\hline \multicolumn{8}{|c|}{ Breakers } \\
\hline \multicolumn{8}{|c|}{ Demolition or rotary hammers } \\
\hline \multicolumn{7}{|c|}{ Plate compactors - Non-vibration reduced } & \\
\hline & Plate compactors - Vibration reduced & & & & & & \\
\hline & Pneumatic hammers & & & & & & \\
\hline & Saws (cut-off) - Masonry cutting & & & & & & \\
\hline & Scabblers & & & & & & \\
\hline & Trench rammers & & & & & & \\
\hline & Water jetting guns & $\mathbb{E}$ & & & & & \\
\hline & Brushcutters (saw cutter) & & & & & & \\
\hline & Chainsaws & & & & & & \\
\hline & Hedge trimmer & & & & & & \\
\hline & Mowers - Hand-guided & & & & & & \\
\hline & Mowers - Ride on & & & & & & \\
\hline & Strimmers - Brushcutter-Strimmer & E & & & & & \\
\hline & Chipping hammers - Chipping weld & & & & & $\mathbb{E}$ & \\
\hline $\operatorname{Imp}$ & act wrenches - drive size: $3 / 8,1 / 2 \& 3 / 4^{\prime \prime}$ & $\mathbb{E}$ & & & & & \\
\hline & Impact wrenches - drive size: $1 "$ & & & & & & \\
\hline & Pedestal grinders & & & & & & \\
\hline Polishers - Angle ( $\mathrm{h}$ & hand-held) - Mop head or soft-backed pad & 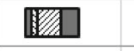 & & & & & \\
\hline Chipping & hammers - Chipping stone, concrete, rust & & & & & & \\
\hline & Rock drills & & 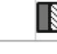 & & & & \\
\hline
\end{tabular}

Fig. 4 Summary vibration magnitudes for common powered hand-tools ( $a_{\mathrm{hv}}$ is the frequency-weighted vibration total value, based on the hand position giving the highest vibration value for that machine) 
Table 2 Information proposed for revision of HSE guidance

\begin{tabular}{llll}
\hline Industry & Tool type & Tool characteristic, & Range \\
& Inserted tool, size, process & $\left(\mathrm{m} / \mathrm{s}^{2}\right)$ & $\begin{array}{l}\text { Initial value } \\
\left(\mathrm{m} / \mathrm{s}^{2}\right)\end{array}$
\end{tabular}

General

Drills

Drills

Drills-Core

Drills-Impact

Grinders-Angle

Grinders-Angle

Grinders-Angle

Grinders-Die

Grinders-Straight

Nail guns

Needle scalers

Needle scalers

Nibblers

Reciprocating saws

Sanders-Random-orbital

Sanders Orbital

Construction

Breakers

Demolition or rotary hammers

Plate compactors

Plate compactors

Pneumatic hammers

Saws-Cut-off

Scabblers

Trench Rammers

Water jetting guns

Forestry/Horticulture

\section{Brushcutters \\ Brushcutter \& Strimmers}

Chainsaws

Hedge trimmers

Mowers-Hand-guided

Mowers-ride on

Engineering

Chipping hammers

Impact wrenches

Impact wrenches

Pedestal grinders

Polishers-angle (hand-held)

Stone working/mining/quarrying

Chipping hammers

Rock drills

Stone hammers

Woodworking

Jigsaws

Routers

Staplers
Standard drill bit

Hole saw

78-107 mm

5 and $8 \mathrm{~mm}$ masonry bit

100-180 mm

125 and $100 \mathrm{~mm}$ Flapper discs

220-300 mm

西

Non-vibration reduced

Vibration reduced

\begin{tabular}{|c|c|c|}
\hline & $7-12$ & 12 \\
\hline & $7-27$ & 18 \\
\hline & $6-14$ & 12 \\
\hline & $4-12$ & 9 \\
\hline & $7-18$ & 14 \\
\hline & $10-21$ & 18 \\
\hline Non-vibration reduced & $9-22$ & 18 \\
\hline Vibration reduced & $2-7$ & 4 \\
\hline & $10-29$ & 25 \\
\hline Masonry cutting & $5-14$ & 13 \\
\hline & $4-14$ & 12 \\
\hline & $13-13$ & 13 \\
\hline & $1-5$ & 4 \\
\hline Saw head & $3-5$ & 5 \\
\hline Strimmer head & $2-6$ & 4 \\
\hline & $5-7$ & 7 \\
\hline & $3-7$ & 6 \\
\hline & $4-8$ & 7 \\
\hline & $3-7$ & 6 \\
\hline Chipping weld & $20-32$ & 31 \\
\hline Drive size: $3 / 8,1 / 2 \& 3 / 4^{\prime \prime}$ & $3-6$ & 5 \\
\hline Drive size: $1^{\prime \prime}$ & $7-11$ & 10 \\
\hline & $2-11$ & 8 \\
\hline Mop head or soft-backed pad & $1-3$ & 3 \\
\hline Chipping stone, concrete, rust & $11-22$ & 20 \\
\hline & $10-28$ & 26 \\
\hline & $7-22$ & 18 \\
\hline & $9-17$ & 11 \\
\hline & $2-3$ & 3 \\
\hline & $2-6$ & 4 \\
\hline
\end{tabular}




\subsection{Indicative Data for Proposed Update to HSE Guidance}

Table 2 shows the information proposed for inclusion in a revision of guidance to the Control of Vibration at Work Regulations 2005, given in HSE guidance book L140 [1]. Table 2 is planned for inclusion as an Annex relating to sourcing vibration magnitude data for vibration risk assessments.

The information in Table 2 provides some guide vibration magnitude values and also indicates that there is a range of values that might be expected for each machine type. The introductory text to table will explain that the 'recommended initial value' vibration magnitudes may be used in combination with exposure durations (trigger times) to make an initial estimate of daily vibration exposures. It will further state that, in many cases, these estimates will be sufficient to determine duties under the regulations and to review control measures and revise them as necessary.

\section{Conclusions}

HAV risk assessments must be suitable and sufficient, identifying the measures required to protect workers. In many cases, sample vibration data and information on exposure times can be quickly combined to give the suitable and sufficient exposure estimates, which show clearly the issues the employer needs to address. A more precise exposure estimate may be required once controls are in place, particularly when it is not clear whether there is a remaining risk which needs to be address (for example by limiting exposure times).

Providing tools designed to simplify HAV risk assessment, such as the rule of thumb, HAV calculator, exposure points and example data, helps to demystify the risk assessment process. Importantly, it enables employers to move from exposure estimation to actively controlling risk as quickly as possible.

Acknowledgments This publication and the work it describes were funded by the Health and Safety Executive (HSE). Its contents, including any opinions and/or conclusions expressed, are those of the authors alone and do not necessarily reflect HSE policy.

Open Access This article is distributed under the terms of the Creative Commons Attribution 4.0 International License (http://creativecomm ons.org/licenses/by/4.0/), which permits unrestricted use, distribution, and reproduction in any medium, provided you give appropriate credit to the original author(s) and the source, provide a link to the Creative Commons license, and indicate if changes were made.

\section{References}

1. HSE: Hand-arm vibration the control of vibration at work regulations 2005 guidance on regulations (L140) (ISBN 0-7176-6125-3). http://www.hse.gov.uk/pubns/priced/1140.pdf (2005). Accessed 4 January 2016

2. European Parliament, Council: Directive 2002/44/EC of the European Parliament and of the Council of 25 June 2002 on the minimum health and safety requirements regarding the exposure of workers to the risks arising from physical agents (vibration), OJ L 177, 6 July 2002, pp. 13-20

3. International Organization for Standardization: ISO 5349-1:2001 mechanical vibration and shock-evaluation of human exposure to hand-transmitted vibration-part 1 General requirements, ISO, 2001

4. European Parliament, Council: Directive 2006/42/EC of the European Parliament and of the Council of 17 May 2006 on machinery, and amending Directive 95/16/EC (recast)., OJ L 157, 9 June 2006, p. 24

5. International Organization for Standardization: ISO 20643:2008 +A1:2012 Mechanical vibration-hand-held and hand-guided machinery - principles for evaluation of vibration emission, ISO, 2012

6. Shanks, E.P., Hewitt, S.M., Pitts, P.M.: Investigation of the relationship between vibration emission and in-use vibration for electrical tools. Can. Acoust. 39(2), 104-105 (2011)

7. International Organization for Standardization: ISO 5349-2:2001 mechanical vibration-Measurement and evaluation of human exposure to hand-transmitted vibration-part 2: practical guidance for measurement at the workplace, ISO, 2001

8. International Organization for Standardization: ISO 8041:2005 human response to vibration-measuring instrumentation, ISO, 2005

9. European Commission: Non-binding guide to good practice with a view to implementation of directive 2002/44/EC on the minimum health and safety requirements regarding the exposure of workers to the risks arising from physical agents (vibrations). http://bookshop.europa.eu/is-bin/INTERSHOP.enfinity/ WFS/EU-Bookshop-Site/en_GB/-/EUR/ViewPublication-Start? PublicationKey=KE7007108 (2008). Accessed 4 January 2016

10. Pitts, P.M., Mason, H.J., Poole, K.A., Young, C.E.: Relative performance of frequency weighting $\mathrm{Wh}$ and candidates for alternative frequency weightings when used to predict the occurrence of handarm vibration induced injuries. Can. Acoust. 39(2), 96-97 (2011) 